\title{
El médico como personaje literario en la Edad Moderna
}

\author{
The doctor as a literary character in the Modern Age
}

Walter Ledermann $D .^{1}$

'Centro de Estudios Humanistas Julio Prado.

\section{Resumen}

El médico ha sido desde la Antigüedad víctima de la ambivalencia afectiva de la población, que lo ama y lo odia de acuerdo a sus éxitos y fracasos. Mientras algunos despotrican contra el gremio, se enorgullecen de ser pacientes del Dr. Tal o Cual, a quien se refieren por su nombre de pila, como queriendo sentar dominio sobre su persona. Los hay quienes lo envidian y desprecian en público sus éxitos, que niegan, y su bienestar económico, que desearían tener. Pero, en general, restando y sumando, la opinión pública hoy en día reconoce el avance de la profesión y valora la imagen del médico, en tanto que antaño, cuando el arte fallaba a menudo y la oferta de curación era escasa, esta imagen solía ser poco favorable. La literatura, que registra los usos y costumbres de cada época, presta valiosa ayuda para conocer los cambios que ha sufrido la apreciación de la labor médica y de sus ejecutantes. Una somera revisión de algunos textos clásicos en que aparece el médico como personaje, pueden ayudarnos a visualizar esta evolución, haciendo la salvedad que sólo podemos presentar un puñadito de ejemplos, para colmo elegidos según nuestro personal juicio y gusto.

Palabras clave: doctor, personaje literario; epidemias; investigación médica; Colegio Médico.

$\mathrm{E}$ 1 médico ha sido desde la Antigüedad víctima de la ambivalencia afectiva de lo población, que lo ama y lo odia de acuerdo a sus éxitos y fracasos. Esta ambivalencia es en parte responsable de los cambios de su imagen en la literatura; sin embargo, pese a la oscilación, de acuerdo al autor, entre héroe y villano, a lo largo de los últimos siglos el juicio literario sobre el médico ha ido mejorando, seguramente por el continuo progreso de la medicina. Por otra parte, las grandes crisis, como guerras, desastres naturales o epidemias, contribuyen a valorar la opinión que la población tiene sobre el quehacer médico.

En una breve revisión de algunos textos clásicos en que aparece el médico como personaje, elegidos de acuerdo a nuestro personal gusto y juicio, y por lo mismo incompleta, Montaigne, Alemán, Cervantes,

\section{Correspondencia a:}

Walter Ledermann Dehnhardt

oncemayor@gmail.com

\section{Abstract}

The doctor has been from de Antiquity a victim of the people's affective ambivalence, who loves and hates him accord his success or failures. Some rant against the medical guild, but are proud to be patients of one or another doctor, more o less celebrated, referring familiarly to him as Tony or Jim. A certain envy hurts the doctor's image, countered by gratitude, but finally, as times goes by, the continuous progress of medicine has been improving the public perception about the medical work. A quick review of the Modern Age literature, personal, whimsical and may be imperfect, from Michel de Montaigne, in the sixteenth century until. A. J. Cronin in the twentieth, shows the evolution of the doctor as a literary character, first as a tricky ignorant, after like a clown, later fighting epidemics and ending as a self-sacrificing medical researcher.

Keywords: doctor, literary character, epidemics, medical research, Medical College.

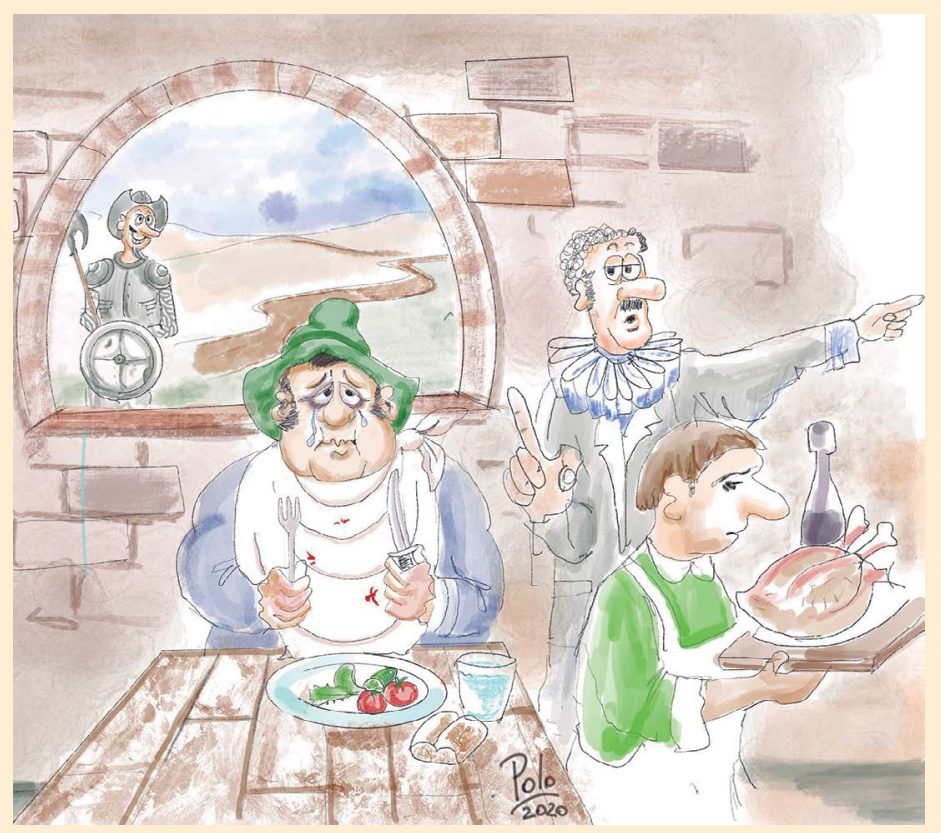


no tenemos de qué y reiráse de nuestra ignorancia. $\mathrm{Y}$ mientras uno quería contar la verdad al Cardenal, el otro le propuso aplicarle corrosivos, fuego y otras linduras, para ganar sus honorarios. Alfarache, que los escuchaba, les pidió clemencia, prometió ayudarles y entre los tres engañaron al eclesiástico fingiendo durante mes estar sanándolo, repartiéndose los beneficios ${ }^{2}$.

\section{Ensayos, Michel de Montaigne, 1580.}

Michel Eyquem de Montaigne (1533-1592), quien sufría del "mal de piedra" (cálculos renales), creía haber heredado tal condición de su abuelo y de su padre, trasmitida por "una gota de semilla" (semen), abomina de los médicos en sus Ensayos:

"Que los médicos me excusen algún tanto mi libertad si digo que merced a esa misma infusión e insinuación fatales, he asentado en mi alma el menosprecio y el odio hacia sus doctrinas. Esta antipatía que yo profeso al arte de sanar es en mi hereditaria. Mi padre vivió setenta y cuatro años, mi abuelo sesenta y nueve, y mi bisabuelo cerca de ochenta, sin que llegaran a probar ninguna clase de medicina; y entre todos ellos, cuanto no pertenecía al uso ordinario de la vida era considerado como droga. Los médicos no se contentan con controlar la enfermedad, sino que además truecan la salud en mal, para asegurar en toda ocasión el ejercicio de su autoridad".

Seguramente escribió esta diatriba presa del dolor al "expulsar una piedra del tamaño de un guisante", pues en otra parte dice tener médicos muy agradables, de quienes acepta sonriente sus consejos para no causarles desagrado, aunque luego los ignora. Pero bastaría para comprender el nivel de su medicina al contar que "he oido decir a Silvio, excelente médico de París, que para que las fuerzas de nuestro estómago no se dejen ganar por la pereza, es conveniente, siquiera una vez al mes, despertarlas con un exceso de bebida..."

\section{Guzmán de Alfarache, Mateo Alemán, 1599}

En España, por la misma época, Mateo Alemán (1547-¿1614?) no le va en saga al francés hablando de los "cirujanos", médicos de toga corta y a veces simples barberos, a quienes presenta, si bien atinados y hábiles en su profesión, harto alejados de la ética. Estando el pícaro Guzmán de Alfarache mendigando a la puerta de un cardenal, espantóse Su Eminencia a la vista de las atroces llagas en una pierna, fingidas con ayuda de una tintura, y encargó a dos cirujanos que curaran al infeliz, con la promesa de una buena recompensa. Éstos procedieron a una detallada anamnesis, examinaron la pierna y el más experimentado descubrió la treta, pero se lo calló, y dijo a su colega en voz alta que la carne estaba "cancerada" y había que quitarla, para asustar al mentiroso. Luego llevó a su colega afuera, le dijo la verdad y le preguntó qué hacer: Si lo dejamos (así), el bien se nos va de las manos, con la honra y el provecho; si lo queremos curar,

\section{Siglo XVII: El médico es sujeto de burlas}

\section{El ingenioso hidalgo don Quijote de La Mancha, Miguel de Cervantes y Saavedra, 1605}

El famoso Sydenham, llamado el Hipócrates inglés respondió a Blakemore, un alumno que le solicitaba la recomendación de un buen texto de estudio, con un breve "lea el Quijote". Hay en esta novela de Cervantes (1547-1616) varias materias médicas de interés: las descripciones de caracteres psicológicos y desórdenes mentales, consejos higiénicos muy acertados a Sancho, nociones de biotipología, y un atinado aforismo, digno de Hipócrates: Al mal de cuya causa no se sabe, milagro es acertar la medicina...

Sin embargo, habiéndolo leído más de tres veces en nuestra vida, tarea que no recomendamos, por innecesaria, ni a nuestros peores enemigos, no recordamos haber encontrado en esta novela médico alguno sino hacia su final definitivo, el de la segunda parte, cuando el Duque, con cruel sentido del humor, designa a Sancho Panza como Gobernador de la Ínsula de Barataria, con el fin de someterlo a continuas bromas. Este médico -no sabemos si verdadero o falso, pero en todo caso siguiendo la farsava apartando con una varita todos los ricos platos que le sirven en su cena al Gobernador. Ante las protestas del pobre Sancho, replica:

- Yo, señor, soy médico, y estoy asalariado en esta ínsula para serlo de los gobernadores della, y miro por su salud mucho más que por la mía, estudiando día y noche, y tanteando la complexión del gobernador para que hago es asistir a sus comidas y cenas, y a dejarle comer de lo que me parece que le conviene y a quitarle lo que imagino ha de hacerle daño y ser nocivo a su estómago; y así mandé quitar el plato de la fruta por ser demasiado húmeda...

Enfurecido, Sancho lo manda a salir de su presencia, amenazando con dar de garrotazos a él y a otros médicos ignorantes, haciendo la salvedad que, a los médicos sabios, prudentes y discretos, los pondré sobre mi cabeza y los honraré como personas divinas.

Esta salvedad no borra la ironía ni la crítica a la actitud autoritaria del gremio médico, con sus mil y una prohibiciones de todo lo grato de este mundo en pro de una utópica perfecta salud. Y tampoco este capítulo disculpa el total silencio a lo largo de tan extensa obra sobre un acertar a curarle cuando cayere enfermo; y lo principal 
personaje tan frecuente y a menudo decisivo en nuestras vidas, lo cual nos hace pensar que a Cervantes o no le agradaban los médicos o no le importaban ${ }^{3}$.

\section{El libro de todas las cosas y otras muchas más, Francisco de Quevedo (1631).}

Francisco de Quevedo (1580-1645), escritor prolífico y burlón, más de una vez se burló de los médicos. En este "Libro de todas las cosas" da sanos consejos a mucha gente, entre ellos a los galenos:

"Si quieres ser famoso médico, lo primero linda mula (hoy 4x4), sortijón de esmeralda en el pulgar, guantes doblados, ropilla larga y, en verano, sombrerazo de tafetán. $Y$ en teniendo esto, aunque no hayas visto libro, curas y eres doctor. Y si andas a pie, aunque seas Galeno, eres platicante (charlatán). Oficio docto, que su ciencia consiste en la mula. Y sobre todo advierte que traigas grande barba, porque no se usan médicos lampiños y no ganarias un cuarto si no parecieses limpiadera (estropajo)-

La ciencia es ésta: dos refranes para entrar en casa, el "qué tenemos" ordinario, "venga el pulso”, “'ha tenido frio?”. Recetar lamedores, jarabes y purgas, para que tenga qué vender el boticario y qué padecer el enfermo. Sangrarle y echarle ventosas; y hecho esto una vez, si durare la enfermedad, tornarlo a hacer hasta que acabe con el enfermo o con la enfermedad. Si vive y te pagan, di que llegó tu hora; y si muere dí que llegó la suya. Pide orines, haz grandes meneos, míralo a lo claro, tuerce la boca.

Por las calles ve siempre corriendo y a deshoras, porque te juzguen por médico llamado para enfermedades de peligro. De noche haz que tus amigos vengan de rato en rato a llamar a tu puerta en altas voces, para que oiga la vecindad: iAl señor doctor, que lo llama el duque! ¿Que está mi señora muriéndose! iQue le ha dado al obispo un accidente! Y con esto visitarás más casas que una demanda, y te verás acreditado, y tendrás horca y cuchillo sobre lo mejor del mundo".

Como si esto fuera poco, en "Premáticas y aranceles", continúa golpeando: "Por las muchas iras, escándalos, destrucciones, muertes y venganzas que en bandos y parcialidades se suelen hacer, vedamos todas las armas aventajadas y dañosas, como son espadas, pistoletes, médicos, cirujanos, boticarios. Y declaramos por enemigos del cuerpo a estos tres últimos". (4).

\section{El médico a palos/El enfermo imaginario, Molière (1666)}

En Francia tenemos dos obras de Molière (1622-1673), no menos célebre que Cervantes, que suelen citarse juntas por su malévola crítica a los médicos y a la medicina ${ }^{5}$. Para Molière los médicos son vanos y su arte inefectivo; su lenguaje es pomposo y críptico; ridículas sus maneras y vestimentas; desaforados y erróneos sus diagnósticos, cuando no falsos e inventados para sacar dinero a sus pacientes.

En sus comienzos había ya escrito "El médico volante", donde aparece Sganarelle, obrilla que, al igual que "El villano médico", fue refundida para originar "El médico a palos", donde tenemos a este personaje alardeando de conocimientos empíricos que ha aprendido siendo ayudante de un médico famoso, vestido ridículamente de verde y de amarillo, como "doctor de loros", y pegando a su mujer. En venganza, ésta lo recomienda para tratar el caso dificilísimo de una importante joven que ha perdido el habla, advirtiendo que tan sabio médico oculta por modestia sus conocimientos y no ejerce a menos que le se le apalee. Tras una tunda de palos acepta Sganarelle ver a la paciente, aunque ya sabe que ésta finge estar muda para evitar una boda que quiere imponerle su padre. De aquí en adelante la burla es continua: ridículos ademanes, palabras "latinas" inventadas sobre la marcha, pócimas estúpidas... El falso médico resume malignamente el quehacer médico en uno de sus parlamentos: La mejor ocupación del mundo porque, lo haga bien o mal, siempre me pagan. Cuando te equivocas, nadie te culpa: la culpa será siempre del muerto.

Esta última frase -nadie te culpa-parece indicar que en el siglo XVII la opinión del médico era muy respetada, a diferencia de este XXI, en que los médicos deben contratar seguros para enfrentar las demandas, justas o injustas, por malpractice.

A diferencia de la burda farsa anterior, en El enfermo imaginario hay, si no más profundidad, algo de sutileza en la crítica al médico, que resumimos en un diálogo de Beraldo: El señor Purgón (que receta "purgas") no sabe de finuras, es un médico de pies a cabeza; un hombre que cree en sus reglas más que en todas las demostraciones matemáticas y consideraría criminal examinarlas; él no ve nada oscuro en la medicina, nada dudoso, ninguna dificultad, nada; y con una impetuosa prevención, una confianza inquebrantable y un sentido común y una razón bestiales, le da duro con lavados y sangrías...La teoría de Beraldo es que en caso de enfermedad no hay que nacer nada, dejar que la naturaleza siga su curso y así nos irá mejor: considerando los tratamientos de su época, no deja de tener razón. Y, más adelante, sigue: cuando un médico te habla de ayudar, socorrer, de aliviar a la naturaleza...de depurar la sangre, templar las entrañas y el cerebro, desahogar el bazo, reacomodar el pecho, fortificar el corazón...y de tener secretos para alargar la vida muchos años, te está contando la novela de la medicina...Escúchalos hablar: son las personas más hábiles del mundo. Vélos actuar: son los más ignorantes entre los hombres.

Martín de Riquer cuenta que el 17 de abril de 1673, mientras personifica a Argón en "El enfermo imaginario”, Moliere se sintió mal en el último intermedio 
bailable, una divertidísima parodia, en latín macarrónico, de la solemnidad de la investidura del grado de Doctor en medicina", falleciendo al término de la representación (6).

Más de algún médico parisién habrá exclamado al saberlo: ¡Castigo de Dios!

\section{Siglo XVIII: El médico como gremio}

\section{Diario del año de la peste, Daniel Defoe (1722)}

Daniel Defoe (1660-1731), famoso por su "Robinson Crusoe”, publicó en 1722 esta novela, más bien un documento, sobre la epidemia de peste bubónica que se abatiera sobre Londres el año 1665. Se ha dicho que para escribirla se basó en apuntes de su tío Henry Foe, pues en su primera edición el autor firmó con las iniciales H.F. La curiosidad de este relato radica en que, por mucho que se hable de las crueles medidas de aislamiento y cuarentena, no hay ningún doctor como personaje, aunque aparece como importante institución el Colegio Médico participando en el control de la epidemia. Casi no hay personajes individualizados; del relator no conocemos ni el nombre ni el de su hermano; hay cuatro protagonistas grupales, que son las víctimas, las autoridades, los médicos y los charlatanes, siendo estos últimos los únicos beneficiados, como se aprecia en este párrafo:

"Otros colocaban avisos para atraer incautos hacia sus albergues, ofreciendo directivas y consejos para caso de infección. También tenían títulos especiosos, como éstos: "Eminente médico holandés, recién llegado de Holanda, donde residió durante toda la época de la gran peste del año último en Ámsterdam y curó a multitud de personas que estaban realmente apestadas.» «Dama italiana recién llegada de Nápoles, posee un raro secreto para evitar la infección, que descubrió gracias a su gran experiencia, y realizó allá maravillosas curaciones durante la última epidemia, en la que murieron 20.000 en un día.» "Anciana dama que ejercitó con gran éxito en la última plaga en esta ciudad, año 1636, da su consejo exclusivamente al sexo femenino. Dirigirse a...»

Para hacer frente a tanta estupidez el Lord Mayor, quien dirigía la lucha contra la epidemia, "designó médicos y cirujanos para aliviar a los enfermos pobres y ordenó al Colegio de Médicos la publicación de instrucciones acerca de remedios baratos para todas las instancias de la enfermedad. La verdad es que esta fue una de las cosas más caritativas y juiciosas que se pudieron hacer en aquel tiempo, pues contribuyó a que la gente no se agrupara frente a las puertas de los dispensadores de recetas, y a que no tomara ciegamente y sin consideración pócimas que daban purga y muerte en lugar de vida. Para dar a conocer estas directivas se consultó al Colegio en pleno; se las calculó especialmente para el uso de los pobres, se recomendaron medicinas baratas y se dieron copias gratis a todo el que las deseara".
Alabando la acción médica, Defoe reconoce la falencia de su arte: "La peste desafió toda medicina; hasta los médicos fueron atrapados por ella, con sus protectores sobre la boca; deambulaban prescribiendo a otros e indicándoles qué hacer, hasta que las señales los alcanzaban y caían muertos, destruidos por el enemigo contra el que batallaban en los cuerpos de otros. No hay duda de que los médicos, con su habilidad, prudencia y aplicación, ayudaron a muchos a salvar sus vidas $y$ restaurar su salud. Pero, sin denigrarlos, hay que decir que fueron incapaces de curar a quienes tenian las señales o estaban infectados antes de pedir su ayuda, como fue caso frecuente".

No olvida Defoe a los cirujanos, relatando que se designan los más discretos y capaces, aparte de los que ya estaban en el lazareto "a los que la City y las franquicias confinarán en los lugares más aptos y convenientes; $y$ cada uno de ellos se limitará a un barrio; y los mencionados cirujanos dentro de sus límites se unirán a las investigaciones para inspeccionar los cuerpos, con la finalidad de que pueda haber un verdadero informe sobre la enfermedad"7.

La aparición en la literatura de las corporaciones médicas y quirúrgicas es, a nuestro juicio, uno de los mayores valores de esta crónica.

\section{Siglo XIX: Los límites de la investigación}

Hacia fines de este siglo el desarrollo de la bacteriología, con los éxitos de Robert Koch, paradigma del investigador médico, así como descubrimientos y logros formidables en todas las áreas de la ciencia, hicieron a muchos escritores soñar con avances médicos hasta hoy día imposibles. Los dos más clásicos y demostrativos que se nos vienen a la mente están separados casi por casi setenta años y son los del trágico Dr. Frankenstein y del infortunado Dr. Jekill, cuyos autores han creado personajes inmortales: la "Criatura" y Mr. Hyde.

\section{Frankenstein o el moderno Prometeo, Mary Shelley (1818)}

Aunque luego de triunfar con su "criatura" Mary Shelley (1797-1851) intentó perseverar en una carrera literaria, la historia de Frankenstein la condenó a ser "escritora de una sola novela". Demasiado conocida para extendernos sobre ella, digamos que la novela se basa en una gran idea, como es la creación de la vida, pero que los métodos utilizados para lograr este milagro son grotescos y risibles, a tal punto que su trama "científica", por así decirlo, se trueca en historia de terror. Obviamente, producir horror fue la intención de la autora, y sólo como género de terror merece ser comentada. Buscar en ella ideas profundas y concederle valores extraordinarios nos 
parece exageración; si la mencionamos aquí es porque por vez primera aparece en la literatura el médico investigador que no repara en la ética para poner límites a su investigación, recibiendo un justo castigo ${ }^{8}$.

\section{El extraño caso del doctor Jekyll y el señor Hyde, Robert Louis Stevenson (1886)}

El tonelaje literario de Robert Louis Stevenson (18501894) supera ampliamente el peso pluma de Mary Shelley: esta nouvelle es buen ejemplo de ello. El doctor Jekyll, apasionado por la ciencia, no roba cadáveres de los cementerios ni ensambla piezas de uno con huesos de otro, intentando luego echar a andar esta maquinaria deforme mediante un shock eléctrico; más científico, más realista y más mesurado, recurre a fórmulas químicas para separar la variable cantidad de personalidad maligna que duerme en todos nosotros. Para su espanto, descubre que en él esta porción maligna es más grande y más fuerte que su parte benigna, tanto así que terminará por imponerse del todo y transformarle en un patológico criminal. Para escapar de esta personalidad malévola, que reaparece una y otra vez por más droga que beba, al Dr. Jekyll no le queda más escapatoria que el suicidio?.

Hay una gran diferencia entre ambos médicos. Mientras Frankenstein rebasa a sabiendas todo límite ético en la busca del conocimiento y recibe por ello merecido castigo, Jekyll busca ayudar a los humanos librándolos del mal, lo cual está lejos de ser éticamente reprobable y, más que merecedor de castigo, viene a resultar víctima de "un accidente de laboratorio". Al menos y modestamente, así nos parece.

\section{Siglo XX: Usando la ciencia para bien y para} mal

\section{El médico asesino en El velo pintado, William Somerset Maugham (1925)}

El descubrimiento de las bacterias patógenas proporcionó a la literatura policial una nueva arma homicida. Un brillante ejemplo de este aporte es "El velo pintado", quizás la mejor novela de William Somerset Maugham (1874-1965), que ya ha sido llevada al cine al menos un par de veces, con Greta Garbo primero y Naomí Watts recientemente ${ }^{10}$.

Kitty, la bellísima esposa del doctor Walter Kane, microbiólogo, es sorprendida por éste en flagrante adulterio semanas después de haber llegado a Tching-Yen, China. Sin decirle que la había descubierto, planea una atroz venganza y la obliga a seguirlo a Mei-tan-Fu, donde hay una epidemia de cólera que quiere estudiar y derrotar, para que la adúltera se contagie y muera, cosa más que probable. Más, quiere el destino que sea él quien enferme y fallezca, diciéndole "fue el perro quien murió", frase que Kitty no entiende y que el autor, a través de otro personaje nos explica:

- Es la última línea de la Elegía, de Goldsmith.

Walter Kane, personaje ambivalente, es considerado por todos, un mártir de la ciencia: sólo su mujer y el frívolo amante saben de su mente retorcida y criminal. Al final de la novela se nos aclara que en realidad no era médico sino microbiólogo, pero para nosotros no tiene importancia, pues se comporta como tal.

Maugham, en cambio, sí era médico, aunque nunca ejerció. Considerado uno de los tres mejores escritores ingleses del siglo XX, siempre se quejó de que se le considerase sólo "popular, nada innovador y, en suma, light"; a nuestro juicio fue insuperable maestro en el relato corto ${ }^{11}$.

\section{El microbiólogo abnegado en Arrowsmith, Sinclair Lewis (1855-1951)}

Sinclair Lewis (1885-1951) Premio Nobel de Literatura 1930, publicó esta singular novela en 1925, y decimos singular porque, a diferencia de otras similares, revela por parte del autor un buen conocimiento de los métodos de la microbiología. Es una de sus tres más célebres y nos presenta la lucha de Martin Arrowsmith, un investigador médico que se debate entre sus ideales científicos y el bienestar económico que podría obtener con sus investigaciones. Ferry y Martin tenían el propósito de avanzar en el estudio del mecanismo exacto de los derivados de la quinina...sólo disponían para los experimentos de los ratones que Ferry habia ideado utilizar en lugar de los monos...Martin había traído consigo diversas razas de Bacillus lepisepticus, microbio que produce la pleuroneumonía de los conejos y su primer trabajo consistió en averiguar si su compuesto contra este bacilo tenía la misma eficacia que contra el neumococo. ¿Qué tal? Siendo hijo y nieto de médicos, se mueve mejor que Maugham en el ambiente de curiosos tanteos propio de un laboratorio de investigación microbiológica; curiosos, sí, porque...¿qué diablos hacían Ferry y Martin probando en bacterias un quimioterápico destinado a un Plasmodium?

Como buen "jovencito" de película norteamericana, Arrowsmith pone la honestidad por encima del dinero fácil y termina trabajando en busca del bien de la humanidad y no de la gloria, de la fama y de la riqueza. Como vemos, se ha dado un paso gigante desde los cirujanos trapaceros del Guzmán de Alfarache al abnegado doctor Arrowsmith ${ }^{12}$.

Esta novela mereció el Premio Pulitzer y fue un éxito en el cine en 1931, con Ronald Colman bajo la dirección de John Ford.

\section{Otro ejemplo de honestidad en La ruta del doctor Shannon, Archibald J. Cronin (1948)}

El británico Cronin (1896-1981), como su compatriota Maugham, era médico y escritor exitoso de best sellers llevados al cine, pero sin lograr la aceptación de la crítica 
de Orange lo echó de Holanda y no le quedó más que embarcarse en la aventura y volver a Inglaterra. En Sedgemoor ocurrió lo más estúpido: su ejército se cayó en una zanja -the Bussex Rhine- y fue masacrado ${ }^{14}$. Como curiosidad, el único médico de la expedición era William Oliver, estudiante de tercero de medicina, quien describiría luego el síndrome de Pickwick antes que Dickens.

En la novela, uno de los sobrevivientes, malherido, es llevado de noche a la casa del doctor Blood, quien entiende que es un rebelde, pero lo atiende igual, en la mesa de la cocina. Sorprendido por una patrulla con las manos en la masa, es decir, en el enfermo, sigue atendiéndolo imperturbable, hasta que ambos, paciente y médico, son llevados a la cárcel. Siguen unos juicios itinerantes, llamados "los juicios sangrientos", y Peter, condenado a muerte, ve luego su sentencia conmutada a ser vendido como esclavo en las Antillas. En Barbados, sus conocimientos médicos le favorecen frente al Gobernador y a su bella hija Arabella. En medio de la confusión generada por el asalto de un galeón español, Blood y otros esclavos ingleses capturan el navío Cinco llagas, que es rebautizado como Arabella. Famoso como pirata, Blood obtiene el perdón real tras la asunción al trono de Inglaterra de Guillermo III de Orange, quien lo designa como Gobernador de Barbados, y se casa con Arabella ${ }^{15}$.

A lo largo de toda la novela el médico se muestra noble al atender a un rebelde perseguido por la justicia, valiente al asumir su sentencia, hábil al conquistar a su amo, ingenioso en sus diálogos con Arabella, impávido ante el peligro en sus combates, bondadoso al perdonar a su suegro... and so on. Pero, discúlpenos Sabatini, ni la necesidad de sobrevivir ni las injusticias sufridas pueden justificar su piratería.

\section{Referencias bibliográficas}

1.- de Montaigne M. De la semejanza entre padres e hijos. En: Ensayos. Edición de Gonzalo Torné. Penguin Clásicos, España 2016; pp. 305-37.

2.- Alemán M. Guzmán de Alfarache. Ediciones Zeus, Barcelona 1968; I (6): 246-53.

3.- de Cervantes M. El ingenioso hidalgo Don Quijote de la Mancha Editorial Ramón Sopena S.A., Barcelona 1968; II (57): 576-82.

4.- Quevedo F. Libro de todas las cosas y otras muchas más. Biblioteca virtual Cervantes. http://www.cervantesvirtual. com/obra/libro-de-todas-las-cosas-y-otras-muchas-mas--0/

5.- Molière. El médico a palos. El enfermo imaginario. Traducción de Rosa María Blanco. Zig-Zag, Santiago de Chile 2005.

6.- de Riquer M, Valverde J M. Historia de la literatura universal. Editorial Planeta S.A., Barcelona 1968:2: 349-56.

7.- Defoe, Daniel. Diario del año de la peste. Traducción de Pablo de Grosschmid. Editorial Seix Barral S.A., Barcelona 1969; pp. 46-52. 
8.- Shelley M W. Frankenstein. Mestas Ediciones, España 2001.

9.- Stevenson R L. El Extraño Caso Del Dr. Jekyll y Mr. Hyde. Penguin Classics, España 2012.

10.- Maugham W S. El velo pintado. Traducción de Romero de Tejada. Plaza \& Janes Editores, S.A. Barcelona 1993.

11.- Cordell R A. Maugham, William Somerset. En: Collier's Encyclopedia. Crowell Collier and Macmillan, Inc, USA 1967; 15: 562-3.

12.- Lewis S. El doctor Arrowsmith. Traducción de Carlos de
Onís, en: Novelas escogidas. Aguilar S.A. de Ediciones. $3^{\text {a }}$ edición. Madrid 1967; pp. 787-1273.

13.- Cronin A J. La ruta del doctor Shannon. Traducción de Joaquín Urnieta. Ed. Hermes, Buenos Aires 1948.

14.- Churchill W. Historia de Inglaterra y de los pueblos de habla inglesa. Traducción de Santiago Ferrari Ediciones Peuser, Buenos Aires 1958; II: 307-16.

15.- Sabatini R. El Capitán Blood. Editorial Molino, Buenos Aires 1948. 